\title{
Bronchial cast extrication in an intubated and ventilated patient
}

\author{
Charles Hamish Coughlan, ${ }^{1}$ Resham Singh Matharu, ${ }^{1}$ Tomasz Kuczynski, \\ Richard Stümpfle²
}

${ }^{1}$ General Intensive Care Unit, Imperial College Healthcare NHS Trust, London, UK ${ }^{2}$ Centre for Peri-Operative Medicine and Critical Care Research, Imperial College Healthcare NHS Trust, London, UK

\section{Correspondence to} Dr Charles Hamish Coughlan; charles.coughlan@nhs.net

Accepted 19 October 2019

Check for updates

(c) BMJ Publishing Group Limited 2019. No commercial re-use. See rights and permissions. Published by BMJ.

To cite: Coughlan $\mathrm{CH}$, Matharu RS, Kuczynski T, et al. BMJ Case Rep

2019:12:e232181

doi:10.1136/bcr-2019-

232181

\section{DESCRIPTION}

A 64-year-old man with a background of bioprosthetic aortic valve replacement presented to his local District General Hospital with a short history of back pain, fever and malaise. On arrival, he was profoundly hypotensive and metaraminol was started for septic shock after a poor response to intravenous fluids. He was admitted to his local intensive care unit and intubated and ventilated due to respiratory failure. Blood cultures were persistently positive for Streptococcus gallolyticus and transoesophageal echocardiography confirmed infective endocarditis with significant mitral and aortic regurgitation and native mitral and prosthetic aortic valve vegetations. He was started on gentamicin and benzylpenicillin and transferred to our specialist hospital for consideration of valve replacement surgery.

On arrival, he required inotropic support, mechanical ventilation and renal replacement therapy. CT imaging of his brain revealed lesions suspicious for septic emboli. CT pulmonary angiography demonstrated pulmonary oedema with large bilateral pleural effusions and a segmental pulmonary embolism (PE). Abdominal imaging was performed to detect underlying colorectal cancer in view of his blood culture results. ${ }^{1}$ No gross lesion was identified.

Sputum culture was positive for methicillinresistant Staphylococcus aureus and he was started on vancomycin. He was placed on a heparin infusion for his segmental PE. Despite achieving a negative fluid balance, he continued to require supplemental oxygen and experienced episodic desaturation on rolling. Chest radiograph confirmed persistent bilateral pleural effusions. After withholding his heparin infusion, a left-sided chest drain was inserted and a large volume serous effusion drained.

Within minutes of this intervention, he desaturated, became hypotensive and developed bloody respiratory secretions. He required $\mathrm{FiO}_{2}$ of 1.0 to maintain normal oxygen saturations. His minute ventilation fell and arterial blood sampling showed $\mathrm{pCO}_{2} 8.5 \mathrm{kPa}$ and $\mathrm{pH} 7.24$. Ventilatory parameters were notable for high peak and plateau pressuresthe latter confounded by the patient's pre-existing pulmonary oedema and effusions. Chest radiograph confirmed adequate siting of the endotracheal tube (ETT) and left-sided chest drain with no pneumothorax, and persistent reticulonodular shadowing. Transthoracic echocardiography showed no cardiac tamponade and no mitral valve incompetence to account for blood pulmonary oedema.

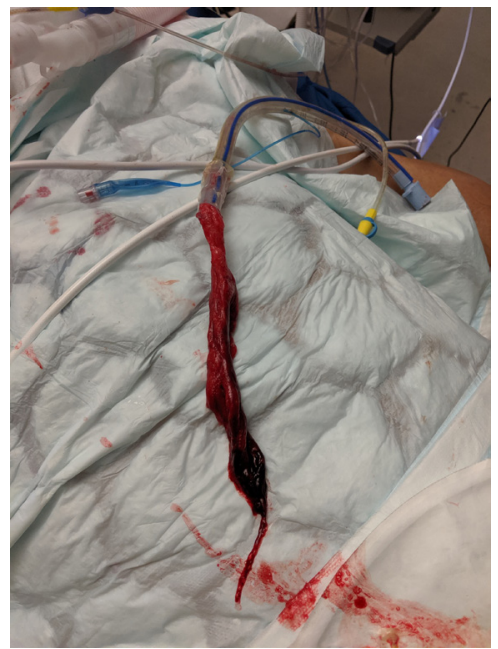

Figure 1 Endotracheal tube with adherent clot.

Given his persistently low oxygen saturations and clinical suspicion of endobronchial obstruction, a decision was made to proceed to flexible bronchoscopy. A large pale blood clot, adherent to the ETT and proximal to the carina, was visualised. Despite multiple attempts, this could not be removed by suction. Owing to the time of night, the resources required for rigid bronchoscopy were unavailable. Having verified a grade I view of the epiglottis, the patient was paralysed, sedated and extubated under suction in an effort to remove the ETT and contiguous clot. The ETT was extricated

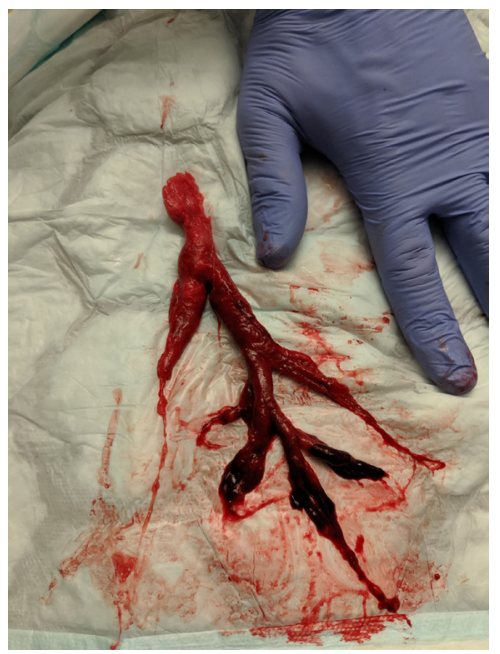

Figure 2 20-cm blood clot bronchial cast of trachea and right and left main bronchi. 
with a $20-\mathrm{cm}$ cast of the trachea and main bronchi (figure 1) and the patient promptly reintubated. This produced an immediate improvement in his ventilatory parameters. Saline wash via bronchoscopy revealed no new bleeding, and inspection of the cast suggested it was old and well formed with blood of different ages (figure 2).

In spontaneously ventilating patients, blood clot bronchial casts typically present with haemoptysis. Common causes include anticoagulant medications, bleeding diathesis, bronchiectasis, infection, malignancy and autoimmune disease. In ventilated patients, blood clots may form insidiously within the airway before presenting with fulminant obstruction. This may manifest as an isolated rise in peak airway pressures, with normal plateau pressures, suggesting airflow obstruction. We suspect that this large clot was dislodged and unmasked when the patient was moved to the right lateral position to facilitate chest drain insertion. Casts are known to move with postural changes; this is exploited in the treatment of plastic bronchitis in spontaneously ventilating patients. ${ }^{2}$

\section{Learning points}

- Circumstances and limited resources sometimes dictate the need to take simple but pragmatic measures to troubleshoot airway problems.

- Bronchoscopy should always be considered when the cause of ventilatory failure is not clear.

- Therapeutic approaches to blood clot bronchial casts in ventilated patients include bronchoscopic clot removal, topical thrombolytic administration and endotracheal tube extrication.
Emergent management of blood clot bronchial casts is not standardised. Several approaches have been described, including bronchoscopic clot retrieval using saline irrigation and suction, forceps, or cryotherapy; topical thrombolytic administration and ETT exchange. ${ }^{3}$ Where available, rigid bronchoscopy offers superior access for forceps and suction catheters in the hands of a skilled operator. Given the lack of therapeutic options at the time, we elected to attempt removal via ETT exchange despite the risk of clot breakage resulting in total occlusion of one or both main bronchi.

The patient was declined further surgery due to an unacceptably high risk of mortality and life-sustaining therapy was withdrawn after discussions with his family.

Contributors CHC conceived the article and wrote the first draft. CHC and RSM gained written consent from the patient's next-of-kin. TK and RS managed the patient at the time of the acute deterioration described in the article, and critically reviewed and amended the manuscript.

Funding The authors have not declared a specific grant for this research from any funding agency in the public, commercial or not-for-profit sectors.

Competing interests None declared.

Patient consent for publication Next of kin consent obtained.

Provenance and peer review Not commissioned; externally peer reviewed.

\section{REFERENCES}

1 Corredoira-Sánchez J, García-Garrote F, Rabuñal R, et al. Association between bacteremia due to Streptococcus gallolyticus subsp. gallolyticus (Streptococcus bovis I) and colorectal neoplasia: a case-control study. Clin Infect Dis 2012;55:491-6.

2 Migliore M, Ciancio N, Giuliano R, et al. Bronchial cast hiding a lung cancer. Multidiscip Respir Med 2012;7:43.

3 Lee H, Leem CS, Lee JH, et al. Successful removal of endobronchial blood clots using bronchoscopic cryotherapy at bedside in the intensive care unit. Tuberc Respir Dis 2014;77:193-6.

Copyright 2019 BMJ Publishing Group. All rights reserved. For permission to reuse any of this content visit

https://www.bmj.com/company/products-services/rights-and-licensing/permissions/

BMJ Case Report Fellows may re-use this article for personal use and teaching without any further permission.

Become a Fellow of BMJ Case Reports today and you can:

- Submit as many cases as you like

- Enjoy fast sympathetic peer review and rapid publication of accepted articles

- Access all the published articles

- Re-use any of the published material for personal use and teaching without further permission

Customer Service

If you have any further queries about your subscription, please contact our customer services team on +44 (0) 2071111105 or via email at support@bmj.com.

Visit casereports.bmj.com for more articles like this and to become a Fellow 